Revista Brasileira de Agricultura Irrigada v.12, nº.4, p. 2814 - 2822, 2018

ISSN 1982-7679 (On-line)

Fortaleza, CE, INOVAGRI - http://www.inovagri.org.br

DOI: $10.7127 /$ rbai.v12n400992

Protocolo 992.18 - 10/07/2018 Aprovado em 11/07/2018

\title{
CRESCIMENTO DE CULTIVARES DE PIMENTÃO EM FUNÇÃO DA ADUBAÇÃO POTÁSSICA
}

Pedro Oliveira Filho ${ }^{1}$, Manoel Valnir Júnior ${ }^{2}$, Cicero Lima de Almeida ${ }^{3}$, Joilson Silva Lima ${ }^{4}$, James do Nascimento Costa ${ }^{1}$, João Paulo Alves da Rocha ${ }^{5}$

\section{RESUMO}

A cultura do pimentão está entre as dez hortaliças de maior importância econômica no mercado. Desse modo, o trabalho tem por objetivo avaliar o efeito de doses diferenciadas de potássio (50, $100,150,200$, e $300 \%$ da recomendada pela análise de solo) em quatro variedades de pimentão (laranja, amarelo, vermelho e verde), em esquema fatorial de $5 \times 4$, com três repetições. $\mathrm{O}$ experimento foi instalado e conduzido no telado agrícola pertencente ao IFCE/Campus Sobral. A avaliação do desenvolvimento vegetativo foi realizada por meio da taxa de crescimento absoluto (TCA) média das variáveis: número de folhas - NF; área foliar - AF; altura da planta - AP; e diâmetro do caule - DC, avaliadas quinzenalmente, além destas variáveis medidas ao final do experimento (75 dias após o transplantio - DAT). Em geral, as variáveis analisadas não foram influenciadas pelas doses de potássio, sendo observado apenas o efeito da variedade sobre a AP e DC. Observou-se que TCA eleva-se até os 30 DAT para o DC, enquanto nas demais variáveis, este crescimento se estende até os 45 DAT. Conclui-se que a adubação potássica não influenciou significativamente no desenvolvimento vegetativo de diferentes variedades de pimentão, desde que fornecido adequadamente a necessidade de nitrogênio.

Palavras-Chave: Capsicum annuum, potássio, casa de vegetação, taxa de crescimento absoluto.

\section{GROWTH OF PEPPER CULTIVARS IN FUNCTION OF THE POTASSIUM FERTILIZATION}

\footnotetext{
ABSTRACT

The culture of the pepper is among the ten vegetables of major economic importance in the market. The objective of this work was to evaluate the effect of different potassium doses (50,

${ }^{1}$ Aluno do Curso de Tecnologia em Irrigação e Drenagem, IFCE Sobral, e-mails: pedrooliveira1998.pfo@gmail.com, jamescosta078@gmail.com

${ }^{2}$ Doutor em Engenharia Agrícola, Professor EBTT do IFCE Sobral, e-mail: valnirjvn@yahoo.com.br

${ }^{3}$ Doutor em Engenharia Agrícola, Técnico em Laboratório do IFCE Sobral, e-mail: cicero.almeida@ifce.edu.br

${ }^{4}$ Doutor em Agronomia/Fitotecnia, Engenheiro Agrônomo do IFCE Sobral, e-mail: joilson.lima@ifce.edu.br

5 Tecnólogo em Irrigação e Drenagem, IFCE Sobral, e-mail: j.paulo25ipueis@gmail.com
} 
$100,150,200$, and $300 \%$ of that recommended by soil analysis) in four varieties of pepper (orange, yellow, red and green), in factorial scheme $5 \times 4$, with three replications. The experiment was conducted in the agricultural greenhouse belonging to IFCE/Campus Sobral. The evaluation of the vegetative development was carried out through the mean absolute growth rate (AGR) of the variables: number of leaves - NL; leaf area - LA; plant height - $\mathrm{PH}$; and stem diameter - SD, evaluated fortnightly, besides these variables measured at the end of the experiment (75 days after transplanting - DAT). In general, the analyzed variables were not influenced by potassium doses, being observed only the effect of the variety on the PH and SD. It was observed that TCA rises up to $30 \mathrm{DAT}$ for SD, while in the other variables, this growth extends up to 45 DAT. Potassium fertilization did not significantly influence the vegetative development of different varieties of pepper, provided that adequately supplied the nitrogen requirement.

Keywords:Capsicum annuum, potassium, greenhouse, absolute growth rate.

\section{INTRODUÇÃO}

A cultura do pimentão (Capsicum annuum L.) se mantém dentre as dez culturas de maior importância econômica no mercado brasileiro de hortaliças, com as maiores áreas de produção localizada no Sudeste, sendo esta a principal região produtora do país. Em 2016 o Brasil plantou 25830 ha, produzindo 54,4 mil toneladas (FAOSTAT, 2018).

Embora seja evidente o crescimento comercial de pimentões coloridos, o grande número de variedades disponíveis no mercado e a pouca informação da exigência nutricional desta hortaliça tem dificultado a seleção de cultivares adequadas aos nichos produtivos, particularmente no estado do Ceará, pela pouca tradição de seu cultivo. Segundo Marouelli e Silva (2012), além de cultivares de frutos vermelhos, quando maduros, existem diversos híbridos coloridos, com cores que variam do marfim ao púrpuro, passando pelo creme, amarelo e laranja, com frutos apresentando três formatos típicos como retangular, cônico e quadrado. Essa diversidade reforça as incertezas de qual variedade seja ideal nos diferentes arranjos de produção.

Segundo Epstein e Bloom (2006), o potássio e o nitrogênio são os nutrientes mais exportados por plantas de pimentão, de modo que maiores doses aplicadas em cobertura e parceladas (SEABRA FILHO, 2017) aumentam a eficiência da adubação, consequentemente pela redução de perdas por percolação e volatilização. Já Silva et al.
(2001) destacam a importância do potássio no metabolismo do pimentão, por melhorar as características físicas e químicas dos frutos, em razão da otimização no processo de transpiração e formação de carboidratos (TAIZ; ZEIGER, 2004). Contudo, quando aplicado excessivamente, pode ocasionar distúrbios fisiológicos como queda na produção e qualidade dos frutos, desbalanceamento nutricional e aumento da pressão osmótica (MARSCHNER, 1995).

Do exposto, considerando o potencial que a cultura do pimentão colorido representa para a horticultura do estado do Ceará, pesquisas que venham facilitar seu cultivo, tornando-o mais eficiente e rentável merecem especial atenção e devem ser incentivadas com vistas a assegurar este pungente e ascendente mercado. Sob tais aspectos estão embasados o estudo ora proposto, no qual se testou níveis de adução potássica em quatro variedades de pimentão colorido, considerando seus efeitos no desenvolvimento da cultura.

\section{MATERIAL E MÉTODOS}

O experimento foi instalado e preparado para um ciclo do pimentão, no período de janeiro a abril de 2018, em ambiente protegido pertencente ao IFCE/Campus Sobral, localizado sob as coordenadas geográficas de $3^{\circ} 41^{\prime} 03^{\prime \prime}$ de latitude Sul e 40²0'24” de longitude a Oeste Greenwich, altitudede70 m.Conforme a classificação de Köppen, clima 
da região é do tipo Aw’, quente, com chuvas de verão. Com temperaturas máximas variando de $36,0^{\circ} \mathrm{C}$ em outubro e de $31,2{ }^{\circ} \mathrm{C}$ em maio e mínimas entre $23,2{ }^{\circ} \mathrm{C}$ em dezembro e $21,0{ }^{\circ} \mathrm{C}$ em julho; as chuvas são da ordem $833 \mathrm{~mm}$ anuais, ocorrendo de janeiro a junho. A umidade relativa média é $68 \%$ e insolação anual é de 2.556 h. (BRASIL, 1990).

O substrato utilizado no experimento, composto por areia e argila (3:1), teve suas características químicas analisadas no Laboratório de Solos e Água do IFCE/Campus Sobral, por meio de amostras deformadas antes da implantação da cultura (Tabela 1).

Tabela 1. Análise química do substrato utilizado no cultivo de quatro variedades pimentão colorido com cinco doses de potássio em casa de vegetação localizado na cidade de Sobral - CE, no período de janeiro a abril de 2018.

\begin{tabular}{cccccc}
\hline $\mathrm{MO}\left(\mathrm{g} \mathrm{kg}^{-1}\right)$ & Potássio $\left(\mathrm{mg} \mathrm{dm}^{-3}\right)$ & Fósforo $\left(\mathrm{mg} \mathrm{dm}^{-3}\right)$ & $\mathrm{CTC}\left(\mathrm{cmol}_{\mathrm{c}} \mathrm{dm}^{-3}\right)$ & $\mathrm{CE}\left(\mathrm{dS} \mathrm{m}^{-1}\right)$ & $\mathrm{pH}$ \\
\hline 62,06 & 0,36 & 18 & 96,66 & 1,46 & 7,6 \\
\hline
\end{tabular}

*MO - matéria orgânica; CTC - capacidade de troca de cátions; CE - condutividade elétrica.

As sementes de pimentão foram semeadas em bandejas de isopor de 128 células, uma semente por célula, em substrato composto por fibra de coco, sob fertirrigação. As mudas foram transplantadas para os vasos trinta dias após a emergência das sementes, iniciando-se a diferenciação dos tratamentos.

As plantas foram conduzidas com espaçamento de $0,6 \mathrm{~m}$ entre plantas e $1,0 \mathrm{~m}$ entre linhas, sendo utilizada uma planta por vaso $\left(20 \mathrm{dm}^{3}\right)$. Para efeito de coleta de dados de crescimento vegetativo e manejo de irrigação, os diferentes estádios de desenvolvimento foram divididos em quatro fases: Fase I - do transplantio até $10 \%$ do desenvolvimento da planta; Fase II - inicia-se no final da fase I e termina antes da floração, que corresponde de 70 a $80 \%$ da cobertura vegetal; Fase III - período de floração e frutificação; e Fase IV - período de maturação, compreendida entre o final da fase III e a colheita.

A adubação foi recomendada e efetuada com base na análise de fertilidade do solo e exigência da cultura (AQUINO et al., 1993). Sendo a adubação de fundação executada aos 10 dias antes do transplantio e as de cobertura parcelas em três vezes aos 30, 45 e 60 dias após o transplantio (DAT), aplicadas manualmente na lateral do vaso. Não houve necessidade de calagem para correção do $\mathrm{pH}$.

O controle fitossanitário foi de caráter preventivo e curativo mediante a incidência esporádica de pragas e doenças. As pulverizações com agroquímicos foram feitas em intervalos quinzenais durante o período da manhã, como forma de amenizar os efeitos ao aplicador e às plantas, cessada aos 65 DAT, segundo recomendação de Oliveira et al, (2013). As pulverizações com defensivo natural (extrato de nim, extrato de fumo e calda bordalesa) foram aplicadas semanalmente, de modo preventivo e sempre aplicadas no fim do dia para evitar danos à parte aérea das plantas. As capinas foram realizadas manualmente de forma a controlar a incidência de plantas invasoras.

O delineamento experimental foi o de blocos casualizados com vinte tratamentos e três repetições, em esquema fatorial $5 \times 4$ (cinco doses de potássio $\mathrm{X}$ quatro variedades de pimentão). Os tratamentos foram compostos a partir da combinação dos fatores dose de potássio e variedades. As doses de potássio (K) utilizadas foram: $\mathrm{K}_{1}(50 \%), \mathrm{K}_{2}(100 \%), \mathrm{K}_{3}$ (150\%), $\mathrm{K}_{4} \quad(200 \%)$ e $\mathrm{K}_{5} \quad(300 \%$ da recomendação prevista para este mineral na análise do solo experimental). As variedades de pimentão colorido (V) foram: $V_{1}$ (Fruto Laranja), $\mathrm{V}_{2}$ (Fruto Amarelo), $\mathrm{V}_{3}$ (Fruto Vermelho) e $\mathrm{V}_{4}$ (Fruto Verde).

O sistema de irrigação utilizado foi o localizado tipo gotejamento, com emissores de vazão $1,5 \mathrm{~L} \mathrm{~h}^{-1}$, pressão de $10 \mathrm{mca}$, um emissor por planta, com uma linha lateral por linha de plantio.

Durante o ciclo da cultura foram realizadas seis avaliações, feitas quinzenalmente, com inicio dois dias após o transplantio. As variáveis analisadas foram: 
altura da planta (AP); diâmetro do caule (DC), medido a três $\mathrm{cm}$ do solo; número de folhas (NF); e área foliar (AF). A área foliar total da planta foi estimada através da técnica do uso de um fator de correção, preconizada por Benincasa (1988). As folhas na planta foram distendidas e feitas as medições de comprimento (C) e largura ( $\mathrm{L}$ ) com uma régua graduada. A partir de cada variável calculou-se a taxa de crescimento absoluto (TCA) para cada período, obtendo-se ao final a TCA média.

Os dados de TCA médio e de crescimento aos 75 DAT de cada variável foram submetidos ao teste de normalidade Kolmogorov-Smirnov. A variável diâmetro do caule, por não apresentar distribuição normal, foi submetida ao teste Kruskal-Wallis e, apresentando efeito significativo, aplicou-se o teste de comparação de médias Stepwise stepdown. As demais variáveis, por apresentarem distribuição normal, aplicou-se a análise de variância pelo teste $\mathrm{F}(P<0,05)$ e, observado efeito significativo, as médias dos tratamentos foram comparadas pelo teste de Tukey $(P<0,05)$.

\section{RESULTADOS E DISCUSSÃO}

Os resultados mostraram que houve diferença significativa $(P<0,05)$ na altura da planta apenas para o fator variedade (Figura 1 ). A variedade verde (V4) apresentou a maior taxa de crescimento absoluta média (TCA) para a altura da planta $\left(1,03 \mathrm{~cm} \mathrm{dia}^{-1}\right)$, diferindo da variedade laranja (V1) com TCA de $0,76 \mathrm{~cm} \mathrm{dia}^{-1}$. As variedades V2 e V3 apresentaram TCA média de 0,88 e 0,92 cm dia $^{-1}$, respectivamente, não diferindo significativamente $(P>0,05) \quad$ das outras variedades.

A taxa de crescimento absoluto da altura da planta (TCA-AP) aumentou consideravelmente até os 45 DAT para todas as variedades, decaindo após essa data (Figura 1A). Esse comportamento deve-se ao início da fase de floração e frutificação, fazendo com que a planta direcione os fotoassimilados prioritariamente para o desenvolvimento reprodutivo, conforme assinala Silva et al. (2010), ao afirmarem que com o crescimento da planta, há também um aumento da necessidade de fotoassimilados para órgãos já formados como folhas, hastes, flores e frutos. Assim, a TCA tende a decrescer com o avanço da idade do ciclo das plantas de pimentão. Esses resultados corroboram com os obtidos por Oliveira et al. (2015), que verificaram maior taxa de crescimento do pimentão, tanto em cultivo convencional como em sistema de plantio direto aos 45 DAT.

A altura das plantas ao final do experimento foi em média $81,2 \mathrm{~cm}$, com diferença significativa entre as variedades V1 e V4 $(P<0,05)$, cuja maior e menor altura foi de $91,3 \mathrm{~cm}$ e $71,6 \mathrm{~cm}$ para a variedade verde (V4) e a variedade laranja (V1), respectivamente (Figura 1B). A altura da planta é influenciada, além de sua genética, também pelo peso do fruto, hábito de crescimento dicotômico, condições ambientais, ciclo da cultura e práticas de manejo cultural (ALBUQUERQUE et al., 2011; OLIVEIRA et al., 2013). 

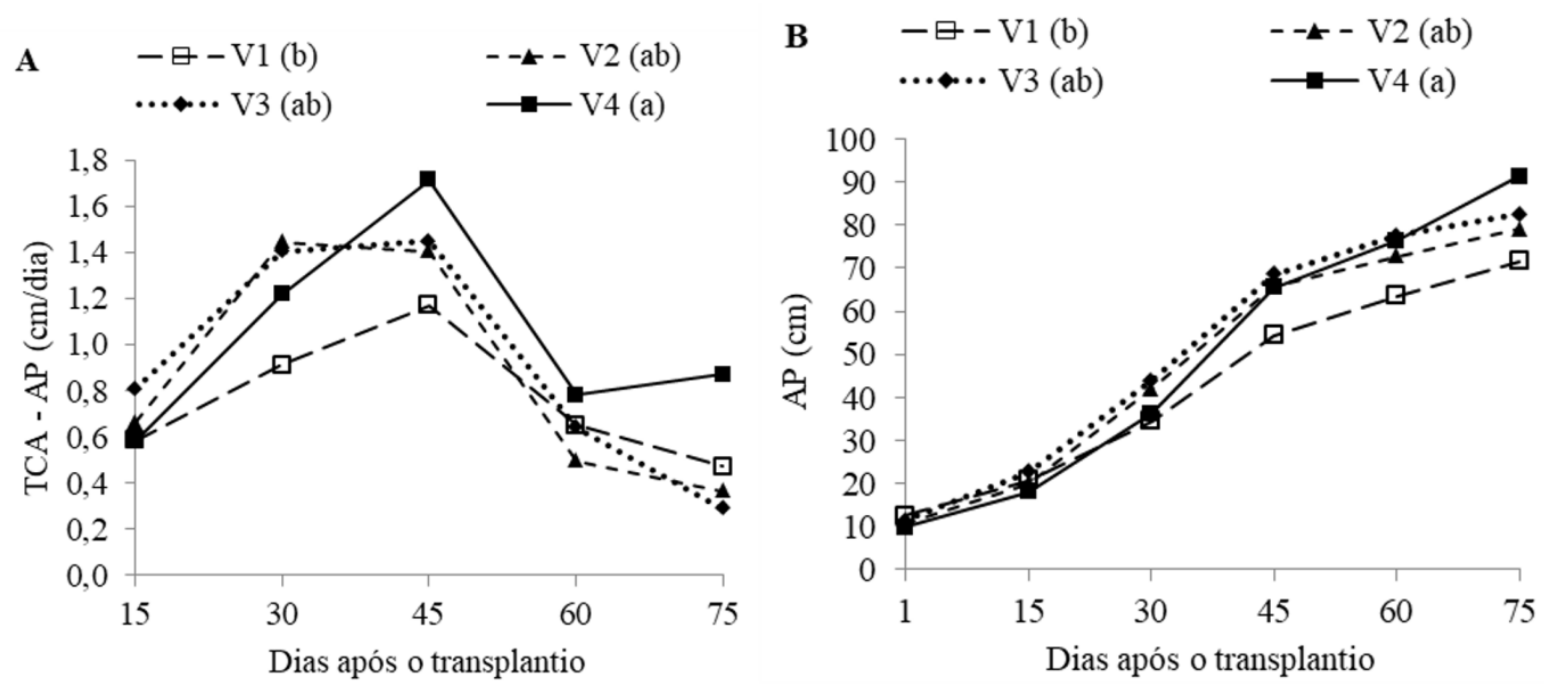

Figura 1. (A) Média da taxa de crescimento absoluto da altura da planta (TCA - AP); e (B) Média da AP para quatro variedades de pimentão obtidas quinzenalmente, submetidas a diferentes doses de potássio. Médias seguidas pela mesma letra não diferem entre si pelo teste de comparação de média de Tukey $(P<0,05)$.

Os valores de altura observado neste trabalho estão de acordo com os apresentados na literatura. Charlo et al. (2011) avaliaram o desenvolvimento de um híbrido de pimentão doce em casa de vegetação e verificaram AP superior a $70 \mathrm{~cm}$ aos 75 DAT, podendo atingir até $140 \mathrm{~cm}$ aos 189 DAT. Albuquerque et al. (2011), ao avaliarem diferentes lâminas e doses de potássio, observaram que a altura da planta variou de 40 a $68 \mathrm{~cm}$ aos 112 DAT, sendo observado efeito significativo do potássio sobre a AP. Contudo, Macêdo e Alvarenga (2005) não observaram efeito significativo da adubação potássica sobre o crescimento do pimentão, resultado que corrobora com o este trabalho.

Diferente da TCA para a AP, a TCA do DC foi crescente somente até os 30 DAT (Figura 2A). Este comportamento também foi observado por Albuquerque et al. (2011) ao avaliarem lâminas de irrigação e doses de potássio no desenvolvimento de pimentão. A precocidade no desenvolvimento do caule deve-se ao fato do mesmo ser o suporte de toda a estrutura da planta (ramos, folhas, flores e frutos), devendo o caule está apto para suportar o crescimento das demais estruturas.

A TCA média do DC foi igual a 0,12 $\mathrm{mm} /$ dia para as variedades amarela (V2) e vermelha (V3), que diferiram estatisticamente $(P<0,05)$ das variedades V1 (laranja) e V4 (verde) que apresentaram a mesma TCA média menor de 0,10 mm/dia. Ao final do experimento (75 DAT) o DC médio foi de 11,7 $\mathrm{mm}$, sendo que o maior DC de $12,6 \mathrm{~mm}$ da variedade V4 diferiu significativamente $(P<0,05)$ da V2 que apresento DC de $11,1 \mathrm{~mm}$ (Figura 2B). Albuquerque et al. (2011) observaram para DC de plantas de pimentão fertirrigadas com diferentes lâminas de irrigação e doses de potássio valor médio de aproximadamente $9,00 \mathrm{~mm}$ aos 77 DAT, valor este abaixo do obtido neste trabalho. 

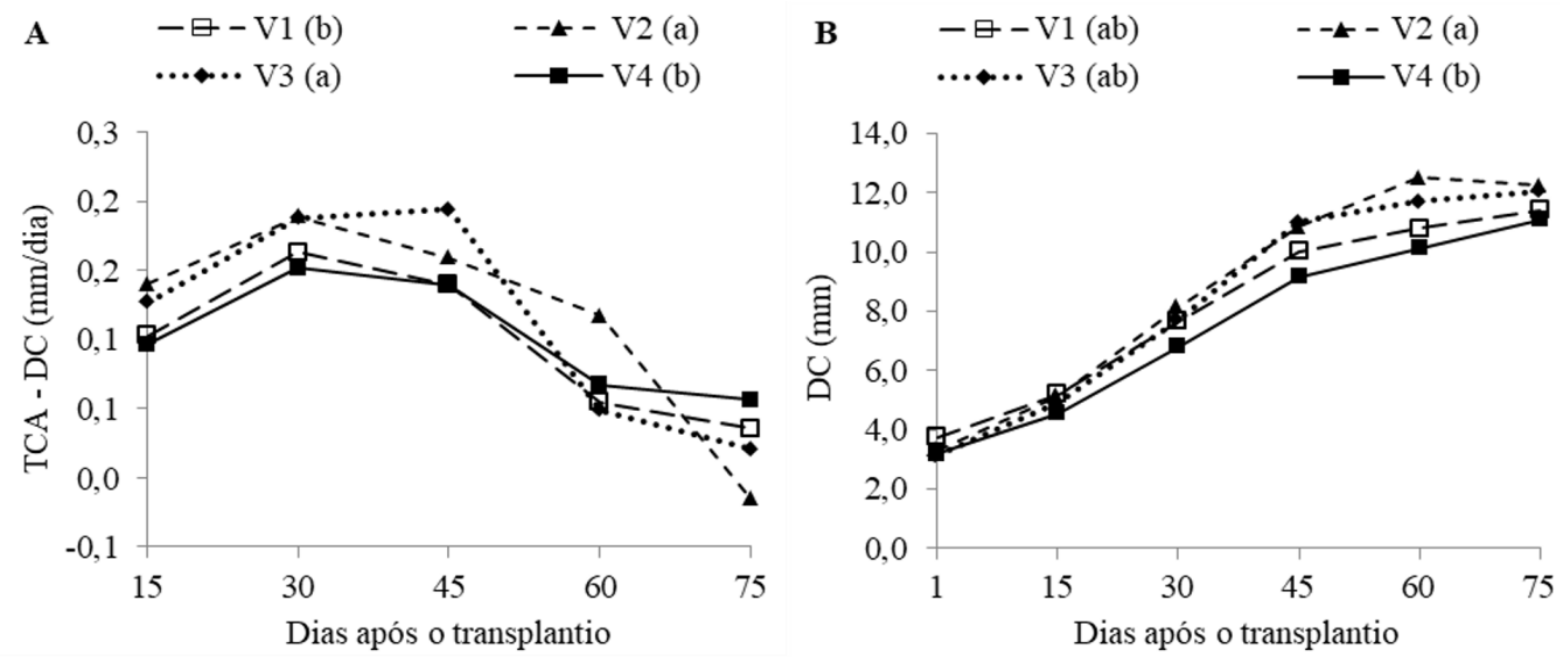

Figura 2. (A) Média da taxa de crescimento absoluto do diâmetro do caule (TCA - DC); (B) Média do DC para quatro variedades de pimentão obtidas quinzenalmente, submetidas a diferentes doses de potássio. Médias seguidas pela mesma letra não diferem entre si pelo teste de comparação de média Stepwise step-down $(P<0,05)$.

De acordo com os resultados, taxas de crescimento absoluto média do NF e da AF não tiveram influência significativa $(P>0,05)$ do fator potássio nem variedade (Figuras 3A e 4A). A maior TCA foi registrada no período de 30 a 45 DAT, com crescimento de 2,52 folhas/dia para NF e de 148,16 cm²/dia para AF, contudo, ao iniciar o período de frutificação esses valores tiveram uma redução considerável, diminuindo para 0,65 folha/dia e $49,06 \mathrm{~cm}^{2} /$ dia respectivamente. Resultados semelhantes foram encontrados por Silva et al, (2015), onde a razão da área foliar (RAF) foi reduzida com a idade da planta. De acordo com os autores op cit. isso ocorre devido à diminuição na disponibilidade de assimilados destinados as folhas, proveniente do aumento da competição entre as partes da planta no decorrer do tempo, especialmente após o início da formação dos frutos.

O NF e a AF apresentaram resultados de 106,5 folhas planta $^{-1}$ e 5761,8 $\mathrm{cm}^{2}$, respectivamente (Figuras 3B e 4B). Trabalho realizado por Charlo et al. (2011) registraram que plantas de pimentão doce, cultivadas em fibra de coco sob condições de casa de vegetação, apresentaram em média 55 folhas aos 75 DAT, valor inferior ao observado neste estudo. Entretanto, os resultados obtidos por Oliveira et al. (2013) e Silva et al. (2011) se assemelham aos deste estudo, com valores de AF aos 75 DAP próximos aos observados neste trabalho. A AF das plantas podem aumentar, chegando a atingir valores superiores a $8 \mathrm{mil}$ $\mathrm{cm}^{2}$ aos 100 DAT (OLIVEIRA et al., 2013; SILVA et al., 2011). 

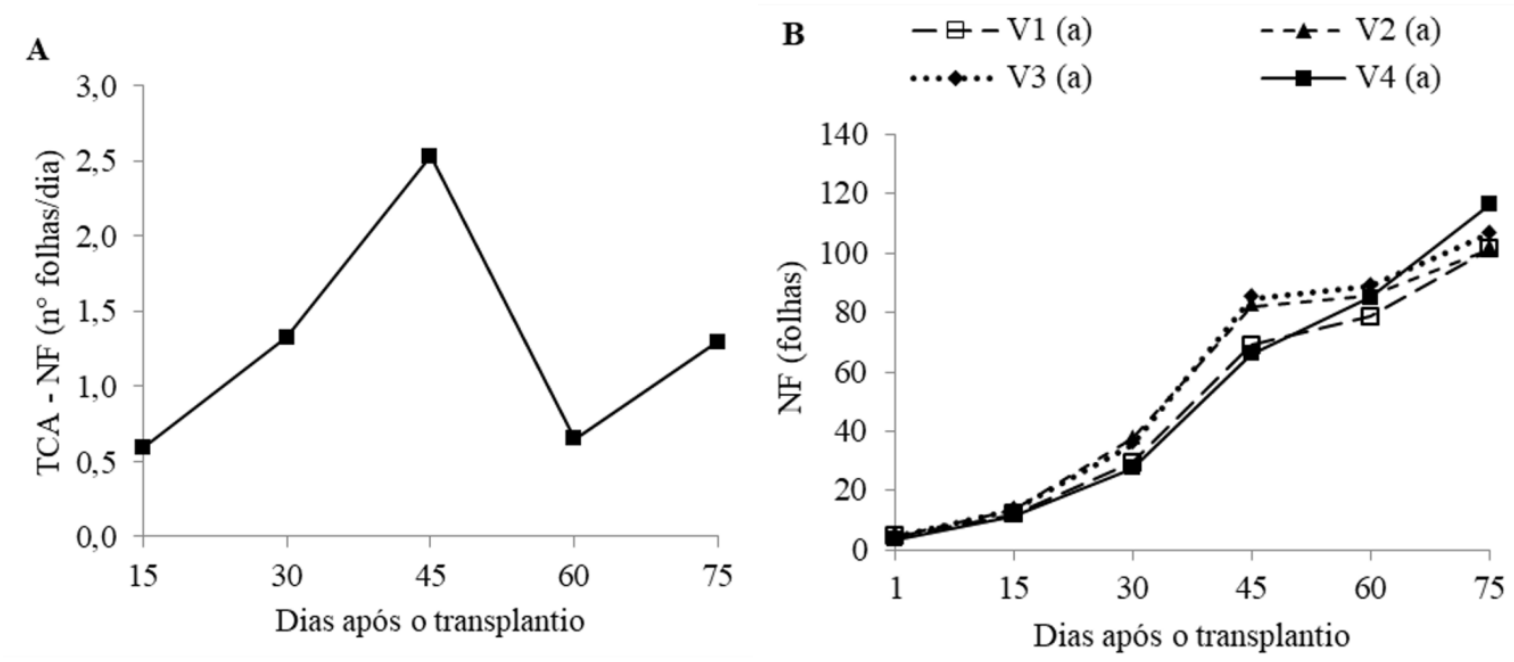

Figura 3. (A) Média da taxa de crescimento absoluto do número de folhas (TCA - NF); e (B) Média do NF para quatro variedades de pimentão obtidas quinzenalmente, submetidas a diferentes doses de potássio. As médias não diferiram entre si pelo teste de comparação de média de Tukey $(P<0,05)$ para os dois fatores.
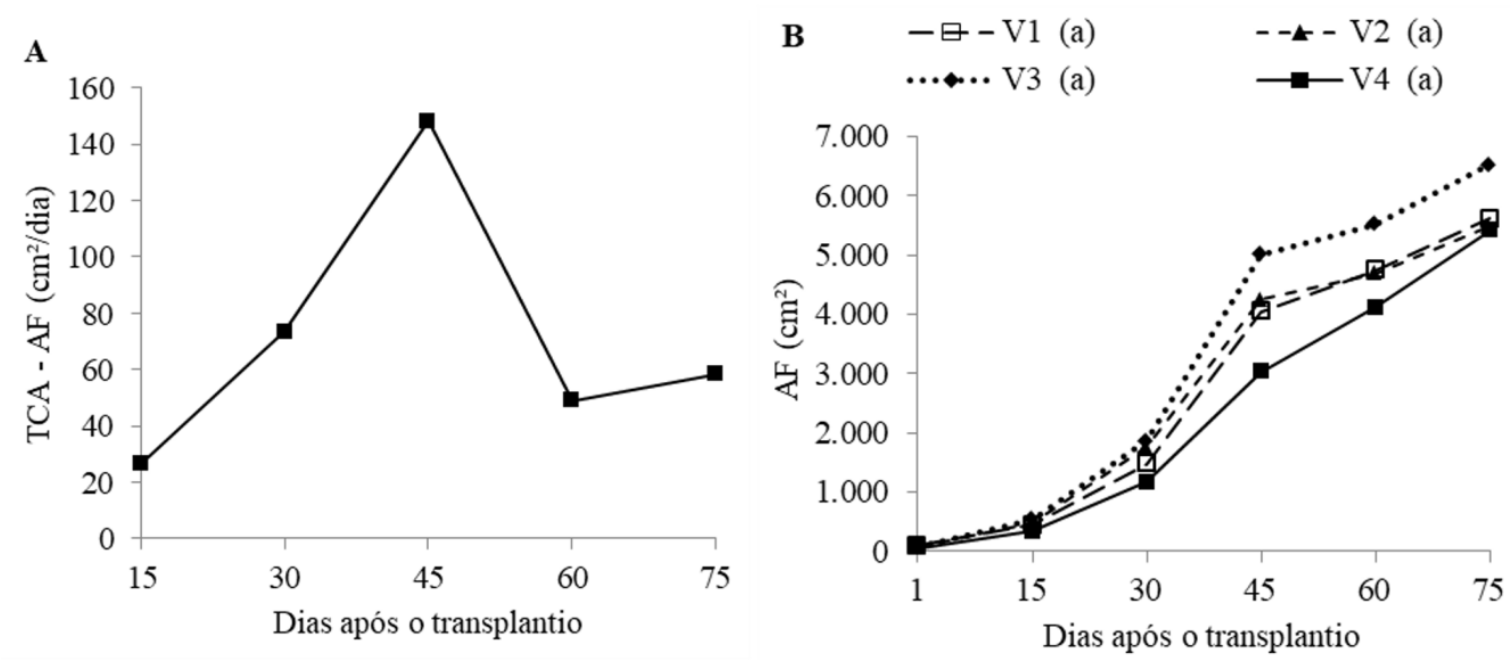

Figura 4. (A) Média da taxa de crescimento absoluto área foliar (TCA - AF) para quatro variedades de pimentão submetidas a diferentes doses de potássio. (B) Média da AF para quatro variedades de pimentão obtidas quinzenalmente, submetidas a diferentes doses de potássio. As médias não diferiram entre si pelo teste de comparação de média de Tukey $(P<0,05)$ para os dois fatores.

A ausência de efeito significativo do fator dose de potássio deve-se a este não está diretamente ligado ao crescimento vegetativo, mas $\operatorname{sim}$ a produção, desenvolvimento e qualidade dos frutos. Epstein e Bloom (2006) ressaltam que o potássio é importante para a translocação e alocação de açúcares da planta para os frutos, propiciando a melhoria de suas características. Costa et al. (2012), ao avaliarem o efeito da adubação potássica na cultura da bananeira, observaram que este nutriente não influenciou no crescimento vegetativo desta frutífera. Além disso, os autores op cit. notaram que os cachos importam 25\% de todo o potássio absorvido pela planta, destacando assim a maior importância do mineral no desenvolvimento reprodutivo.

Em geral, a ausência de efeito significativo na TCA média das variáveis de crescimento avaliadas neste trabalho deve-se, possivelmente, ao fornecimento adequado de nitrogênio $(\mathrm{N})$ às plantas, principal nutriente responsável pelo crescimento vegetativo. De acordo com Malavolta et al. (1997), o N estimula a formação e o desenvolvimento de gemas floríferas e frutíferas, assim como a vegetação, pois faz parte da constituição de enzimas, coenzimas, vitaminas e proteínas, que participam da absorção iônica, 
fotossíntese, respiração, multiplicação e diferenciação celular. Véras et al. (2015) observaram que plantas de pimentão que receberam urina de vaca como fertilizante, fonte rica em nitrogênio, apresentaram crescimento na área foliar em função do aumento da dose do adubo aplicada, evidenciando o efeito positivo do nitrogênio sobre o desenvolvimento vegetativo da cultura. Silva et al. (2009) também verificaram que a adubação potássica não influenciou o número de folhas emitidas e o diâmetro da copa de plantas de coqueiro anão, tendo seu efeito apenas no número de frutos produzidos reafirmando o efeito do potássio no desenvolvimento reprodutivo.

\section{CONCLUSÕES}

De acordo com os resultados, o crescimento vegetativo do pimentão não foi influenciado diretamente pelo fornecimento de potássio à planta.

A altura da planta e o diâmetro do caule apresentaram efeito significativo para os quatro tipos de pimentão avaliados, influenciados pelas características genéticas de cada variedade.

\section{AGRADECIMENTOS}

Ao Conselho Nacional de Desenvolvimento Científico e Tecnológico CNPq pela concessão de bolsa de Iniciação Científica ao primeiro autor.

\section{REFERÊNCIAS BIBLIOGRÁFICAS}

ALBUQUERQUE, F. S.; SILVA, E. F. F.; ALBUQUERQUE FILHO, J. A. C.; NUNES, M. F. F. N.; Crescimento e rendimento de pimentão fertigado sobdiferentes lâminas de irrigação e doses de potássio. Revista Brasileira de Engenharia Agrícola e Ambiental, v.15, n. 7, p.686-694, 2011.

ARAgÃo, V. F. Produção de Pimentão
(Capsicumannuum) em Diferentes Níveis de Nitrogênio e Lâminas de Irrigação. 2005.Dissertação (Mestrado em irrigação e drenagem) - Universidade Federal de Campina Grande, Campina Grande.

BENINCASA, M. M. P. Análise de crescimento de plantas. Jaboticabal: FUNEP, 1988. 42p.

BRASIL. Ministério da Agricultura. Plano Estadual dos Recursos Hídricos do Ceará: dados climatológicos de Sobral - Ce(1961 1988). Brasília, 1990.

CHARLO, H. C. O.; OLIVEIRA, S. F.; CASTOLDI, R.; VARGAS, P.F.; BRAZ, L. T.; BARBOSA, J. C. Growth analysis of sweet pepper cultivated in coconut fiber in a greenhouse. Horticultura Brasileira,v. 29,n. 3, p. 316-323, 2011.

COSTA, F. S.;COELHO, E. F.;BORGES, A. L.;PAMPONET, A. J. M.; SILVA, A. A. S. M.; AZEVEDO, N. F.; Crescimento, produção e acúmulo de potássio em bananeira'Galil 18' sob irrigação e fertilização potássica. Pesquisa Agropecuária Brasileira, v. 47, n. 3, p.409-416, 2012.http://dx.doi.org/10.1590/S0100204X2012000300013.

EPSTEIN, E.; BLOOM, A.J. Nutrição mineral de plantas: princípios e perspectivas. 2.ed. Trad.. Londrina: EditoraPlanta, 2006. 392p.

FAOSTAT - Food and Agriculture Organization of the United Nations. Dados de area e produção de pimentão no Brasil. Disponível <http://www.fao.org/faostat/en/\#data/QC> Acesso em: 10 jul. 2018.

MACÊDO, L. DE S.; ALVARENGA, M. A. R. Efeitos de lâminas deágua e fertirrigação potássica sobre o crescimento, produçãoe qualidade do tomate em ambiente protegido. Ciência e Agrotecnologia, v.29, p.296-304, 2005. 
MALAVOLTA, E.; VITTI, G.C.; OLIVEIRA, S.A. de. Avaliação do estado nutricional de plantas: princípios e aplicações. 2.ed. Piracicaba: Potafos,1997. 319p.

MARSCHNER, $H$. Mineral nutrition of higher plants. Academisc Press, 1995. 889p.

MAROUELLI, W. A.; SILVA, W. L. C. Ministério da Agricultura, Pecuária e Abastecimento - Irrigação na cultura do pimentão, Circular Técnica 101,1ª edição, Brasília, DF, 2012.

OLIVEIRA, A.D.; CARVALHO, D.F.; PEREIRA, J. B. A.; PEREIRA, V. C.; Crescimento e produtividade do pimentão em dois sistemas de cultivo. Revista Caatinga, v. 28, n. 1, p. $78-89,2015$.

OLIVEIRA, F. A.; DUARTE, S. N.; MEDEIROS, J. F.; DIAS, N. S.; SILVA, R. C. P.; LIMA, C. J. G. S.; Manejos da fertirrigação e doses de $\mathrm{N}$ e $\mathrm{K}$ no cultivo de pimentão em ambiente protegido. Revista Brasileira de Engenharia Agrícola e Ambiental, v.17, n.11, p.1152-1159, 2013.

SEABRA FILHO, M. Manejo da supressão e das freqüências de irrigação $e$ da fertirrigação nitrogenada na cultura do girassol. 2017. 110 f. Tese (Doutorado em Engenharia Agrícola) - Universidade Federal do Ceará, Fortaleza.

SILVA, M. A. G.; BOARETTO, A. E.; FERNANDES, H. G.; BOARETTO, R. M.; MELO, A.M.T.; SCIVITTARO, W.B. Características químicas de um latossolo adubado com uréia e cloreto de potássio em ambiente protegido. Scientia Agrícola, v.58, n.3, p.561-566, 2001.

SILVA P. I. B.; NEGREIROS, M. Z.; MOURA, K. K. C. F.; FREITAS, F. C. L.; NUNES, G. H. S.; SILVA, P. S. L.; GRANGEIRO, L. C.; Crescimento de pimentão em diferentes arranjos espaciais. Pesquisa Agropecuária Brasileira, v. 45, n. 2, p. 132-139, 2010.

SILVA, R. A.; CAVALCANTE, L. F.; HOLANDA, J. S.; PAES, R. A.; MADALENA, J. A. S.; Crescimento e produção do coqueiro anão verde fertirrigado com nitrogênio e potássio. Revista Caatinga, v.22, n.1, p.161-167, 2009.

TAIZ, L.; ZEIGER, E. Fisiologia vegetal. Porto Alegre: ArtMed, 2004. 719p.

AQUINO, A. B.; AQUINO, B. F.; HERNANDEZ, F. F. F.; HOLANDA, F. J. M.; FREIRE, J. M.; CRISÓSTOMO, L. A.; COSTA, R. I.; UCHÔA, S. C. P.; FERNANDES, V. L. B. Recomendações de adubação e calagem para o Estado do Ceará. Fortaleza. Fortaleza: Imprensa Universitária, 1993. 248p.

VÉRAS, M. L. M; MELO FILHO, J. S. M; ALVES, L. S; IRINEU, T. H. S; SILVA, G. G; ANDRADE, R; Influência da aplicação de urina de vaca em pimentão (CapsicumannuumL.) em função de adubos orgânicos. Agropecuária Tecnica, v. 36, n. 1, p. 222-228, 2015. 